The 10th International Conference on Coasts, Ports and Marine Structures (ICOPMAS 2012)

Tehran, Iran, 19-21 Nov. 2012

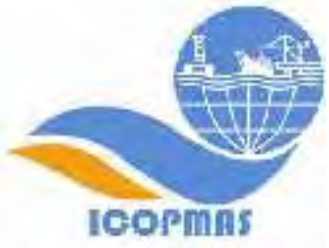

\title{
STUDY OF DESIGN WATER LEVEL ELEVATIONS IN HOTSPOTS OF HORMOZGAN COASTLINE
}

\author{
Matin Rafipour Langeroudi ${ }^{1}$, Amin $\operatorname{Ilia}^{2}$, Farhad Darabinia $^{3}$, Mohammadreza Allahyar ${ }^{4}$
}

Key Words: Design Water level elevations, Hormozgan coastal areas, Mike 21

\begin{abstract}
In this paper, design water level elevations due to wave, tide, wind and barometric pressure are calculated in hotspots including the ports of Kong, Lengeh, Shahid Rajaiee, Kuhmobarak, Sirik and Khuran. The effect of global water level rise is also considered. This modelling is performed utilizing MIKE21 developed by DHI Water and Environment. In order to calculate wave and tide setup, comprehensive and exhaustive studies of wave propagation and tidal levels modelling, which have been performed in last parts of Monitoring and Modeling Project of Coastal Zones of Hormozgan, are used. Also, wind-induced water level variations model is developed to calculate wind setup in various return periods. The results of the study present values of setup due to above mentioned phenomena which can be used in marine structures designs.
\end{abstract}

\section{Introduction}

Sea level is a measurable quantity and it can be generally defined as the results of some influences, including tides, waves, atmospheric pressure, winds, thermal effect, seismic activity (tsunami), vertical land movement, oceanographic effects such as El Niño, etc., which affect the height of sea surface (Aung et al. 1998). The study of coastal erosion, the gradual change of coastline, the cross-shore profile change and the safe design of coastal structures such as groins and jetties is a function of design water level in coastal areas.

Zervas (2001) analyzed monthly mean sea level (MSL) variations for 117 stations of the National Ocean Service's (NOS) National Water Level Observation Network (NWLON) having between 25 and 146 years of data. In this study, monthly MSL data up to the end of 1999 are used to calculate linear trends, and to obtain the average seasonal cycle, the residual time series, and the autoregressive coefficient of the residual with accurate estimates of standard errors. Bondar (2007) have been analyzed the water budget of the Black Sea and the sea level variations at different coastal zones for highlighting the influence of the river - sea interactions. Huang et al. (2008) evaluated GEV model for frequency analysis of annual maximum water levels in the coast of United States.

In this paper, study of design water level elevations in hotspots of Hormozgan coastline is performed utilizing MIKE21. The values of setup due to wave, tide, wind and barometric pressure, along with setup due to global sea level rise are calculated in the return periods of 2 ,

\footnotetext{
${ }^{1}$ Graduate Research Associate, Fara Darya Arshe Consultants, matin.rafipour@gmail.com

${ }^{2}$ Graduate Research Associate, Fara Darya Arshe Consultants, amin.ilia@gmail.com

${ }^{3}$ Graduate Research Associate - Fara Darya Arshe Consultants - f.darabi@faradarya.com

${ }^{4}$ General Director of Ports \& Coasts Engineering - Ports \& Maritime Organization - allahyar@pmo.ir
} 
5, 10, 20,100 years in hotspots of Hormozgan province coasts. These values can be effectively used in designing of marine structures.

\section{Study area}

Hormozgan coastal areas are located between Jask Port on the Oman Sea from the east, and Javad Al Aemmeh Port on the Persian Gulf from the west (i.e. between N57 45', E25 $38^{\prime}$ and $\mathrm{N} 53^{\circ} 5^{\prime}, \mathrm{E} 27^{\circ} 5^{\prime}$ ). These areas are critically important since Persian Gulf is one of the most strategic waterways in the world due to its importance in world oil transportation. Also, many important Iranian ports like Shahid Rajaee (the biggest trading port of Iran), Shahid Bahonar and Lengeh, in addition to Qeshm Island have been located there which are important both economically and politically. Fig.1 presents coastal areas and important ports of the study area.

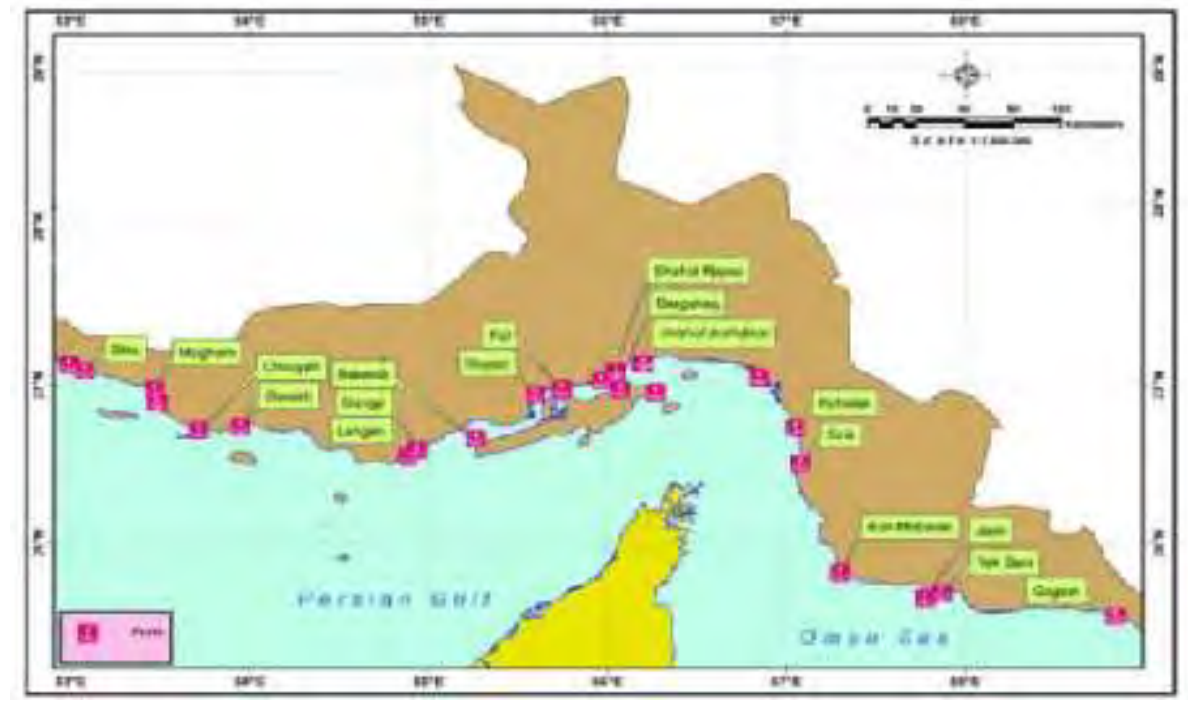

Fig.1) Hormozgan coastal area

\section{Methodology}

In order to study design water level elevations due to wave, wind and tide, precise recognition and analysis of these phenomena is required. Hence, local wave propagation and tidal levels modeling for duration of 28 years, which have been performed by MIKE21 numerical model in last phases of the project, are used. Wave model calibration has been done by recorded data of 8 measurement stations in coastal areas of Hormozgan. After sensitivity analysis of the model, White capping and Bottom friction have been considered as calibration coefficients. Tidal model has been also calibrated and validated by recorded data of more than 20 tidal level measurement stations. More details about these models can be found in references [5] and [6].

In this study, to simulate wind-induced water level elevations, MIKE21 Flow FM-HD is developed. Also, water level elevations due to barometric pressure, along with global sea level rise (equal to $4.8 \mathrm{~mm} /$ year), are considered [1]. Water level elevations values due to above mentioned phenomena in 28-year period are calculated for return periods of 2, 5, 10 , 20 and 100 years by utilizing one-dimensional EVA module of Mike Zero software.

In below sections, concepts of setup due to each mentioned phenomenon along with calculation methods of setup values are described in details.

\section{Wave setup}

When a train of waves propagates toward the shore, at some point, depending on the wave characteristics and nearshore bottom slope, the waves will break. Landward of the point of wave breaking a surf zone will form where the waves dissipate their energy as they decay across the surf zone. 
As the waves approach the breaking point there will be a small progressive set down of the mean water level below the still water level. This setdown is caused by an increase in the radiation stress owing to the decreasing water depth as the waves propagate toward the shore. The setdown is maximum just seaward of the breaking point. In the surf zone, there is a decrease in radiation stress as wave energy is dissipated. This effect is stronger than the radiation stress increase owing to continued decrease in the water depth. The result is a progressive increase or setup of the mean water level above the still water level in the direction of the shore. This surf zone setup typically is significantly larger than the setdown that occurs seaward of the breaking point.

In this study, a one-dimensional numerical model called LITPACK-LITDRIFT has been used to calculate wave-induced setup. In fact, this model investigates nearshore sediment transportation rate and nearshore currents due to wave. Meanwhile, other applications of this software are wave transfer along the cross-shore profile and calculation of water level variations as the result of wave breaking in coastal areas. In this software, wave -induced water level variations are determined from integrated momentum equation along cross-shore:

$$
-\frac{1}{\rho} \frac{\partial \bar{S}_{\mathrm{xx}}}{\partial \mathrm{x}}=\mathrm{g}(\mathrm{D}+\mathrm{b}) \frac{\partial \mathrm{b}}{\partial \mathrm{x}}
$$

Where Sxx is cross-shore radiation stress; D is water depth; $b$ is wave-induced water level variations; $g$ is gravitational acceleration and $\rho$ is water density [9].

The inputs of the model are bathymetry profile and wave characteristics including significant wave height, peak wave period and mean wave direction. After extracting time series of wave characteristic in each hotspot from the wave propagation model at $10 \mathrm{~m}$ depth, time series of significant wave height are saved as dfs0 file. In next step, significant wave height values based on prevailing direction in each point are calculated for return periods of 2, 5, 10, 20, 10, 20 and 100 years by utilizing one-dimensional EVA module of Mike Zero software. Then, corresponding peak wave periods are determined. This wave data along with bathymetry profile is applied to LITDRIFT model. The model transfers each wave toward the coastline and calculates water level variation due to wave along the profile.

\section{Tide setup}

The tide is the rise and fall of sea levels generated by the gravitational attraction of the sun and moon on the oceans and the equal and opposite centrifugal forces owing to the rotation of the earth-sun-moon system. In the Persian Gulf and the Oman Sea, the major water level variations are due to tidal phenomenon. The rise in water level due to tide is defined as tide setup. Water level variations are significantly affected by nearshore hydrography, bottom friction, Coriolis acceleration, and resonant effects. Water and land elevations in the coastal zone are referenced to a variety of tidal datums in different regions of the world and for different purposes. Some of these datums are [9]:

MSL: The average height of all tide elevations (usually on an hourly basis) averaged over a 19-year period

LLW: The lowest of the low water levels

HHW: The highest of the high water levels

MHHW: The 19-year arithmetic mean of only the higher of each pair of high water levels in a mixed tide

MLHW: The 19-year arithmetic mean of only the lower of each pair of high water levels in a mixed tide

MHLW: The 19-year arithmetic mean of only the higher of each pair of low water levels in a mixed tide

MLLW: The 19-year arithmetic mean of only the lower of each pair of low water levels in a mixed tide 
Each lunar and solar component has a period that has been determined from astronomical analysis and a phase angle and amplitude that depend on local conditions and are best determined empirically. Eight major lunar and solar components with their common symbol, period, approximate relative strength (depending on location), and description are listed in Table 1. The components combine in different ways at each coastal location and are affected by local hydrography, bottom friction, resonance and so on, to produce the local tide.

Table 1) Tidal parameters

\begin{tabular}{cccc}
\hline Symbol & Period(hour) & approximate relative strength & Sources \\
\hline M2 & 12.42 & 100 & Main lunar, semidiurnal constituent \\
\hline S2 & 12.00 & 46.6 & Main solar, semidiurnal constituent \\
\hline N2 & 12.66 & 19.2 & $\begin{array}{c}\text { Lunar constituent due to monthly } \\
\text { variation in moon's distance }\end{array}$ \\
K2 & 11.97 & 12.7 & Soli-lunar, semidiurnal constituent \\
K1 & 23.93 & 58.4 & Soli-lunar constituent \\
O1 & 25.82 & 41.5 & Main lunar, diurnal constituent \\
\hline P1 & 24.07 & 19.4 & Main solar, diurnal constituent \\
\hline
\end{tabular}

Many numerical models have been developed for hydrodynamic studies in last decades. In present studies, Mike21 has been used because of its wide facilities and reliable results. Moreover, some parameters such as Coriolis force, wind forcing, bed friction, and Eddy viscosity can be considered in calculations.

To obtain tidal levels, first, tidal parameters of O1, K1, S2, M2, Z0 have been calculated by utilizing tidal option of Mike 21 toolbox. In this stage, time series of surface elevation, obtained from the tidal model in last parts of monitoring and modeling project of coastal zones of Hormozgan, have been used as model input. After obtaining the tidal parameters, chart datum (CD), low low water (LLW) and high water (HHW) can be calculated by using below equations.

National Cartographic Center (NCC) of Iran is using a "modified" Indian Spring Low Water (ISLW) as CD. Its formula is [7]:

$$
\mathrm{CD}=\mathrm{Z} 0-1.1(\mathrm{M} 2+\mathrm{S} 2+\mathrm{K} 1+01)
$$

Also, following equations have been used to obtain LLW, HHW, MHHW, MLHW, MHLW, and MLLW [9].

$$
\begin{aligned}
& \mathrm{LLW}=\mathrm{Z} 0-(\mathrm{M} 2+\mathrm{S} 2+\mathrm{K} 1+\mathrm{O} 1) \\
& \mathrm{HHW}=\mathrm{Z} 0+(\mathrm{M} 2+\mathrm{S} 2+\mathrm{K} 1+\mathrm{O} 1) \\
& \mathrm{MHHW}=\mathrm{Z} 0+(\mathrm{M} 2+\mathrm{K} 1+\mathrm{O} 1)) \\
& |\mathrm{MLHW}=\mathrm{Z} 0+| \mathrm{M} 2-(\mathrm{K} 1+\mathrm{O} 1) \mid \\
& \mathrm{MHLW}=\mathrm{Z} 0-|\mathrm{M} 2-(\mathrm{K} 1+\mathrm{O} 1)| \\
& \mathrm{MLLW}=\mathrm{Z} 0-(\mathrm{M} 2+\mathrm{K} 1+\mathrm{O} 1)
\end{aligned}
$$

Usually MHHW is used as tide-induced setup in design of marine structures.

\section{Wind setup}

A wind system over nearshore shallow coastal waters or shallow inland water bodies can generate large water level fluctuations if the wind system is sufficiently strong and the water body is shallow over a large enough area. Wind system can cause both a rise (setup) and fall (setdown) of the water level at different locations and times. Setup is commonly predominating in vertical magnitude, lateral extent, and duration. This occurs when the 
forward velocity of the wind is close to the celerity of a shallow water wave over which the wind system is traveling. It takes time for this wave to develop so the wind must travel for a significant period of time.

In order to calculate wind setup, the wind-induced water level variations model is developed using MIKE21 Flow FM-HD. Parameters' characteristics of model are as follows:

Table 2: The calibration parameters of the water level variations model

\begin{tabular}{|c|c|}
\hline Parameters & Description \\
\hline Density & Barotropic state equation \\
\hline Eddy viscosity & Smagorinsky formulation with constant coefficient of 0.28 \\
\hline Bed resistance & Constant Maninng number in domain equal to $32\left(\frac{\mathrm{m}_{\mathrm{m}} / \mathrm{s} / \mathrm{s}}{\mathrm{s}}\right.$ \\
\hline Coriolis forcing & Varying in domain \\
\hline Wind forcing & Varying in time and domain \\
\hline
\end{tabular}

Also, wind friction values have been considered about 0.001255 and 0.00245 for wind speeds of 7 and $25(\mathrm{~m} / \mathrm{s})$, respectively. When the wind speed is between mentioned values, wind friction is calculated by linear interpolation. More details about these models can be found in references [4]

After running the model for 28-years period, time series of water level variations in the study area are extracted from the model and saved as dfs 0 file (Mike21 time series format).

In the next step, values of water level variations in various return periods must be calculated by using statistical methods. Hence, wind setup values in return periods of 2, 5, 10, 20, 50 and 100 years are calculated by utilizing one-dimensional EVA module of Mike Zero software.

\section{Setup due to barometric pressure}

The effect of barometric pressure on sea level variations is calculated by using following formula

$$
\Delta \mathrm{p}=\Delta \mathrm{h} \rho \mathrm{g}
$$

and substituting the typical values. Here $\Delta$ p represents atmospheric pressure difference $\rho$ is density of seawater, $g$ is acceleration due to gravity and $\Delta \mathrm{h}$ is the change of sea level height due to pressure. The seawater density and standard atmospheric pressure at sea level is taken $1.025 \frac{\mathrm{g}}{\mathrm{ml}}$. and $1009.28 \mathrm{hPa}$, respectively.

The depression of the water surface under high atmospheric pressure, and its elevation under low atmospheric pressure, is often described as the inverted barometer effect (Crowder 1995). The water level does not adjust itself immediately to a change of pressure and it responds to the average change in pressure over a considerable area. Changes in sea level due to barometric pressure seldom exceed $30 \mathrm{~cm}$ (Aung et al. 1998). It is also to be noted that a decrease of barometric pressure by $1 \mathrm{hPa}$ may cause a $\sim 1 \mathrm{~cm}$ rise in sea level and vice versa. In this study, setup due to barometric pressure is calculated using the measured data sets of barometric pressure in Lengeh, Queshm, Bandar-e- Abbas and Jask synoptic stations. The location of these stations and a sample of pressure changes are presented below. 


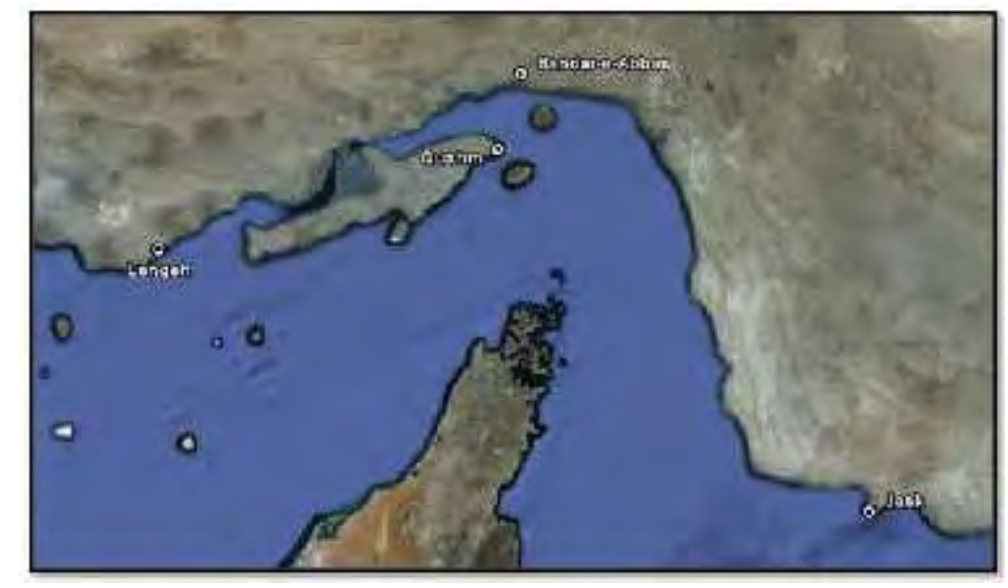

Fig.2) Location of Synoptic stations in the study area

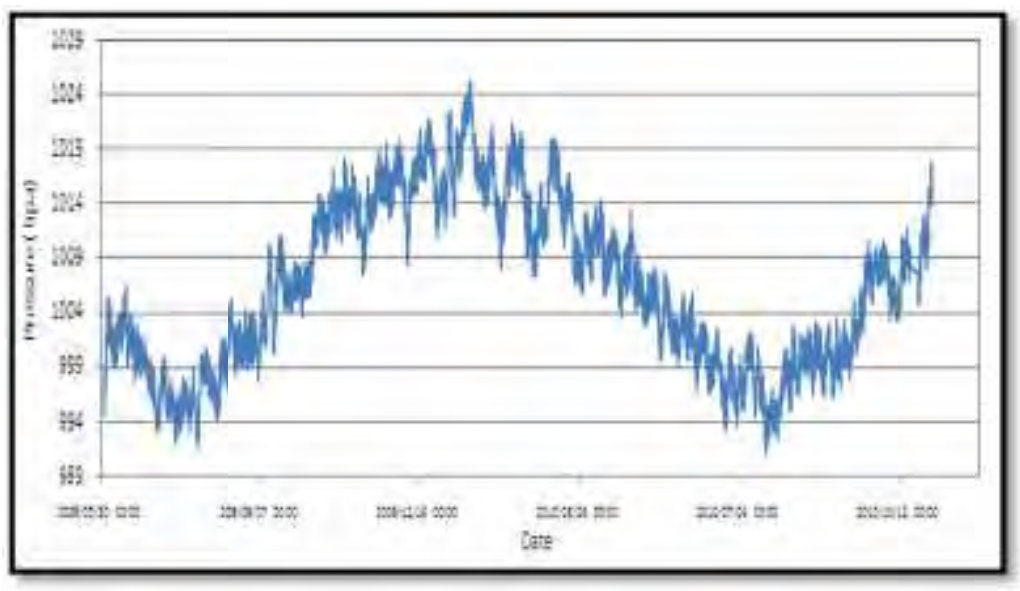

Fig.3) Pressure changes from first of June 2009 to 31th of October 2010 in Lengeh synoptic station

To calculate setup due to barometric pressure in each station, at first the mean barometric pressure for each station are calculated, then barometric pressure variations than the mean pressure are computed for total duration of pressure data. Finally, the water level corresponding to the barometric pressure variations are calculated by using 3-14 formula.

In the next step, values of setup in various return periods must be calculated in each synoptic station by using statistical methods. Hence, setup values in return periods of 2, 5, 10, 20, 50 and 100 years are calculated by means of EVA module of Mike Zero software.

\section{Global sea level rise}

There are two main factors affect the volume or mass of the ocean, leading to long-term changes in eustatic sea level. The first is thermal expansion: as ocean water warms, it expands. The second is from the contribution of land-based ice due to increased melting. The major store of water on land is found in glaciers and ice sheets.

Sea level rise is one of several lines of evidence that strongly support the view that the climate has recently warmed. It is very likely that human-induced (anthropogenic) warming was responsible for the sea level rise observed in the latter half of the 20th century. The average sea level rise rate is considered $4.8 \mathrm{~mm} /$ year [1] which is equal to following values in return periods of $2,5,10,20,50$ and 100 years:

Table 3) Global sea level rise

\begin{tabular}{|c|c|}
\hline Return Period (years) & Sea Level Rise (m) \\
\hline 2 & 0.010 \\
\hline 5 & 0.024 \\
\hline
\end{tabular}




\begin{tabular}{|c|c|}
\hline 10 & 0.048 \\
\hline 20 & 0.096 \\
\hline 50 & 0.240 \\
\hline 100 & 0.480 \\
\hline
\end{tabular}

\section{Results and conclusion}

In this study, setup due to wave, tide, wind and barometric pressure, along with setup due to global sea level rise were calculated in hotspots of Hormozgan coastline, including the ports of Lengeh, Suza, Kong, Kuh Mobarak, Rajaie, Sirik and Khuran. Below sections presents results of setup study in the Port of Sirik.

\section{Wave setup}

In order to determine wave setup, wave characteristics, involving significant wave height, peak wave period and mean wave direction, have been extracted from wave propagation modelling for a point in front of Sirik station with depth of $10 \mathrm{~m}$. Fig.5 represents bathymetry profile of this point. Moreover, Table 4 represents final results of wave setup calculation. As can be seen, the maximum values of wave setup for return periods of 50 and 100 years are $65 \mathrm{~cm}$ and $71 \mathrm{~cm}$, respectively.
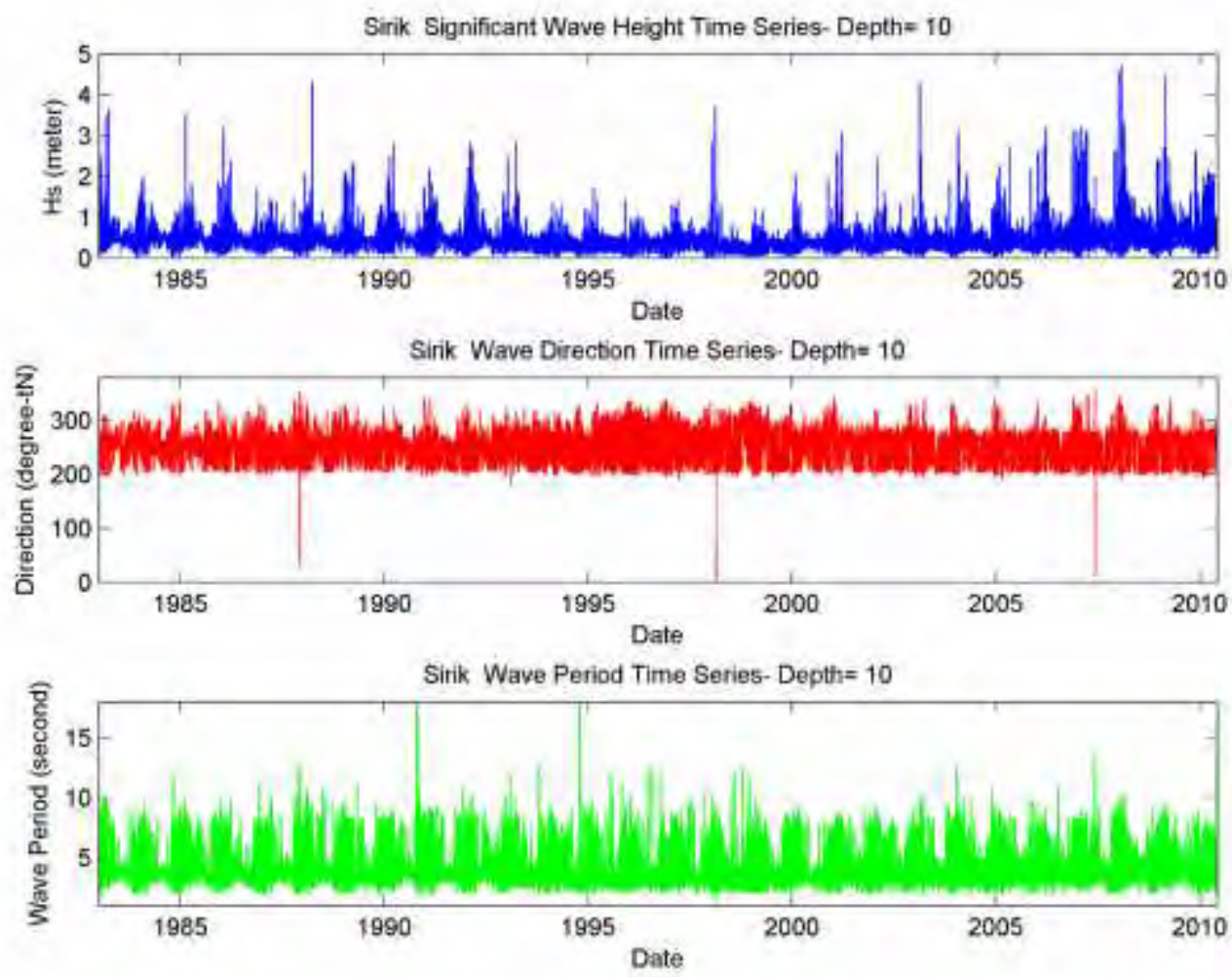

Fig.4) The time series of Wave height, Period and direction for port of Sirik in $10 \mathrm{~m}$ depth 


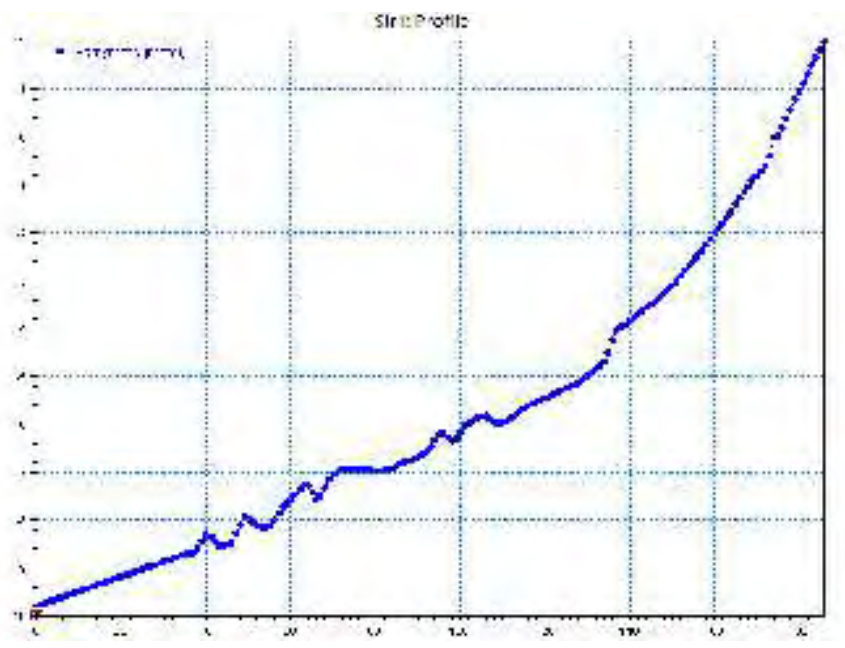

Fig.5) Bathymetry profile used for a point in front of Sirik station

Table 4) Results of maximum wave setup in front of Sirik station for wave of $10 \mathrm{~m}$ depth for various return periods

\begin{tabular}{|c|c|c|c|c|c|}
\hline Direction (degree) & Type of Distribution & Return Period (years) & Hs (m) & Period (sec) & $\begin{array}{l}\text { Wave Setup } \\
\text { (m) }\end{array}$ \\
\hline \multirow{6}{*}{202.5} & \multirow{6}{*}{ Weibull } & 2 & 1.08 & 5.96 & 0.14 \\
\hline & & 5 & 1.27 & 6.40 & 0.16 \\
\hline & & 10 & 1.39 & 6.67 & 0.17 \\
\hline & & 20 & 1.54 & 6.97 & 0.18 \\
\hline & & 50 & 1.65 & 7.19 & 0.19 \\
\hline & & 100 & 1.76 & 7.39 & 0.20 \\
\hline \multirow{6}{*}{225} & \multirow{6}{*}{ Weibull } & 2 & 1.12 & 6.07 & 0.18 \\
\hline & & 5 & 1.35 & 6.58 & 0.20 \\
\hline & & 10 & 1.50 & 6.89 & 0.21 \\
\hline & & 20 & 1.69 & 7.25 & 0.23 \\
\hline & & 50 & 1.83 & 7.51 & 0.24 \\
\hline & & 100 & 1.97 & 7.75 & 0.25 \\
\hline \multirow{6}{*}{247.5} & \multirow{6}{*}{ Weibull } & 2 & 1.86 & 7.58 & 0.27 \\
\hline & & 5 & 2.37 & 8.41 & 0.33 \\
\hline & & 10 & 2.71 & 8.91 & 0.37 \\
\hline & & 20 & 3.13 & 9.50 & 0.42 \\
\hline & & 50 & 3.45 & 9.91 & 0.46 \\
\hline & & 100 & 3.77 & 10.30 & 0.50 \\
\hline \multirow{6}{*}{270} & \multirow{6}{*}{ Weibull } & 2 & 2.82 & 9.08 & 0.41 \\
\hline & & 5 & 3.65 & 10.16 & 0.52 \\
\hline & & 10 & 4.21 & 10.81 & 0.59 \\
\hline & & 20 & 4.92 & 11.56 & 0.62 \\
\hline & & 50 & 5.44 & 12.09 & 0.65 \\
\hline & & 100 & 5.97 & 12.59 & 0.71 \\
\hline \multirow{6}{*}{292.5} & \multirow{6}{*}{ Weibull } & 2 & 0.74 & 5.06 & 0.15 \\
\hline & & 5 & 0.94 & 5.62 & 0.18 \\
\hline & & 10 & 1.08 & 5.96 & 0.19 \\
\hline & & 20 & 1.25 & 6.37 & 0.21 \\
\hline & & 50 & 1.38 & 6.65 & 0.23 \\
\hline & & 100 & 1.51 & 6.92 & 0.24 \\
\hline
\end{tabular}

\begin{tabular}{|l|c|c|c|c|c|}
\hline \multirow{3}{*}{ All Directions } & \multirow{3}{*}{ Weibull } & 2 & 2.78 & 9.02 & 0.40 \\
\cline { 3 - 5 } & & 5 & 3.50 & 9.97 & 0.50 \\
\cline { 2 - 5 } & 10 & 3.98 & 10.55 & 0.57 \\
\hline
\end{tabular}




\begin{tabular}{|c|c|c|c|c|}
\cline { 2 - 4 } & 20 & 4.60 & 11.23 & 0.65 \\
\cline { 2 - 5 } & 50 & 5.05 & 11.70 & 0.67 \\
\cline { 2 - 5 } & 100 & 5.51 & 12.15 & 0.71 \\
\hline
\end{tabular}

\section{Tide Setup}

In order to determine tide setup, water level variations have been extracted from tidal modelling for a point in front of Sirik station with depth of $10 \mathrm{~m}$. Fig. 6 shows time series of water level variations for this point. Tidal datums and parameters obtain from Matlab programming and Mike 21 toolbox. In order to provide standard results, chart datum (CD) is subtracted from values of tidal datums and parameters. The results of tidal datums and parameters have been represented in Table 5 and Table 6, respectively. Mean higher high water (MHHW) will be used as tide setup in this point for later calculations.

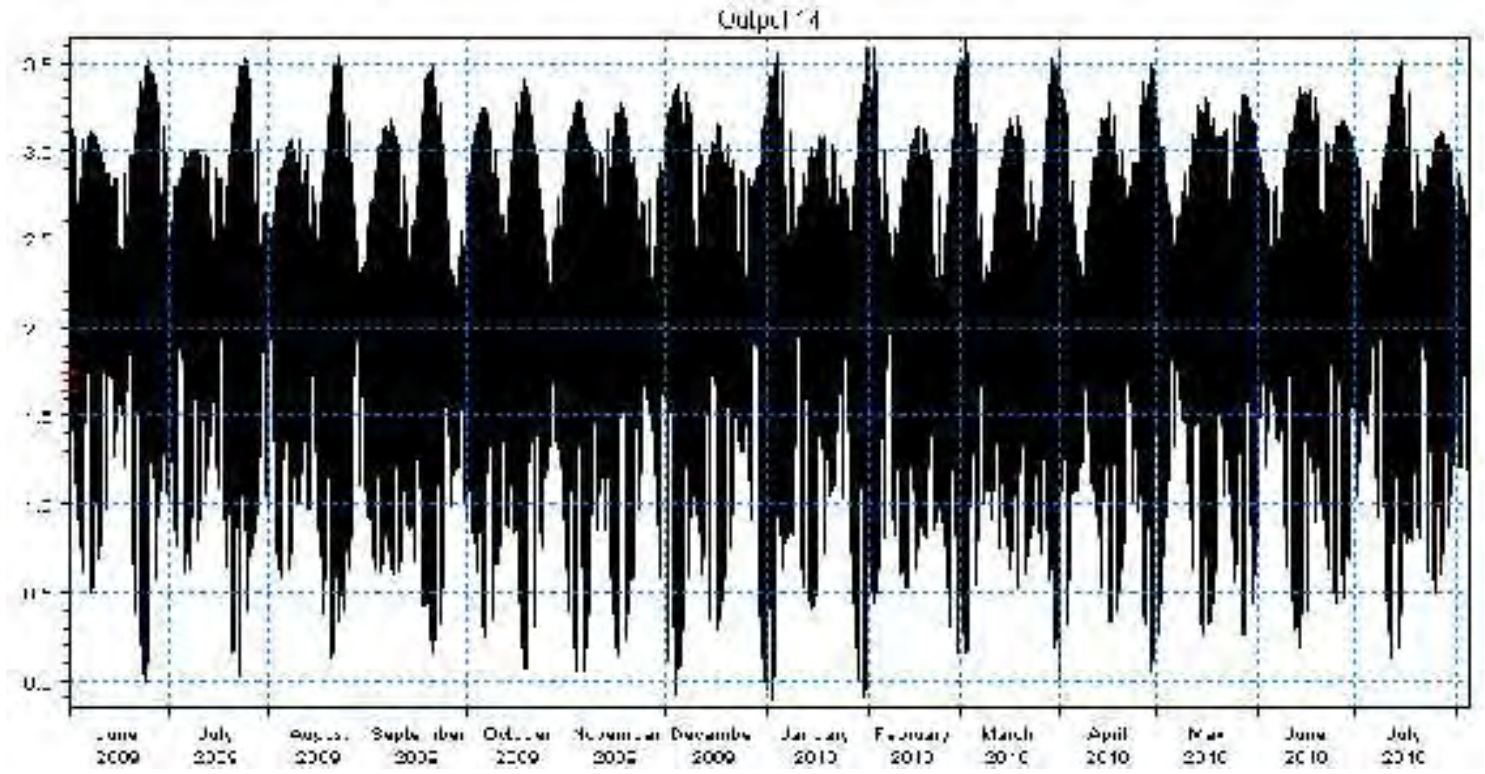

Fig.6) Time series of water level variations for a point in front of Sirik station with depth of $10 \mathrm{~m}$

Table 5) Tidal datums for a point in front of Sirik station with depth of $10 \mathrm{~m}$

\begin{tabular}{|c|c|c|c|c|c|c|c|}
\hline Level & LLW & HHW & MSL & MHHW & MLHW & MHLW & MLLW \\
\hline Height (m) & 0.18 & 3.76 & 1.98 & 3.35 & 2.23 & 1.57 & 0.45 \\
\hline
\end{tabular}

Table 6) Tidal parameters period for a point in front of Sirik station with depth of $10 \mathrm{~m}$

\begin{tabular}{|c|c|c|c|c|}
\hline $\mathbf{Z 0}$ & S2 & M2 & O1 & K1 \\
\hline 1.98 & 0.34 & 0.89 & 0.22 & 0.34 \\
\hline
\end{tabular}

\section{Wind Setup}

In order to determine wind setup, water level variations have been extracted from windinduced water level variations modelling for a point in front of Sirik station with depth of 10m. Fig.7 shows time series of water level variations for this point. The probability and return period of water level variations based on Weibull distribution has been presented in Figure 8. Also, Table 7 represents final results of wind setup calculation. 


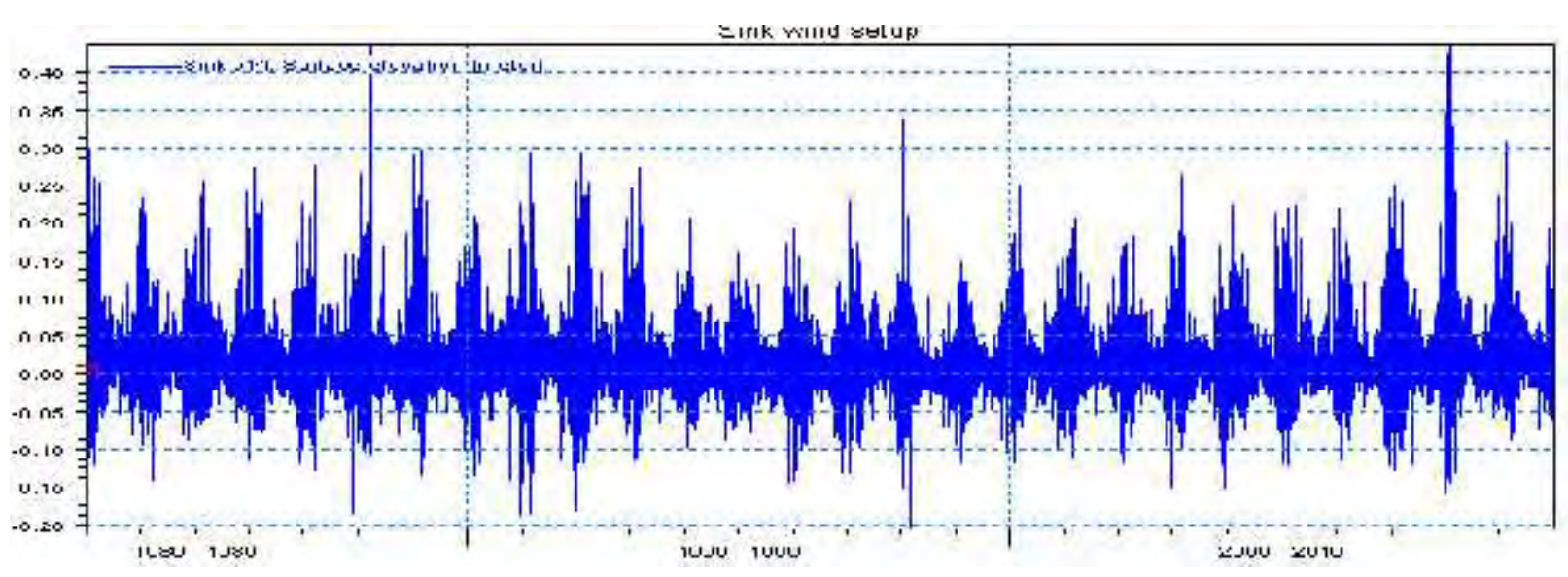

Fig.7) Time series of water level variations for a point in front of Sirik station with depth of $10 \mathrm{~m}$

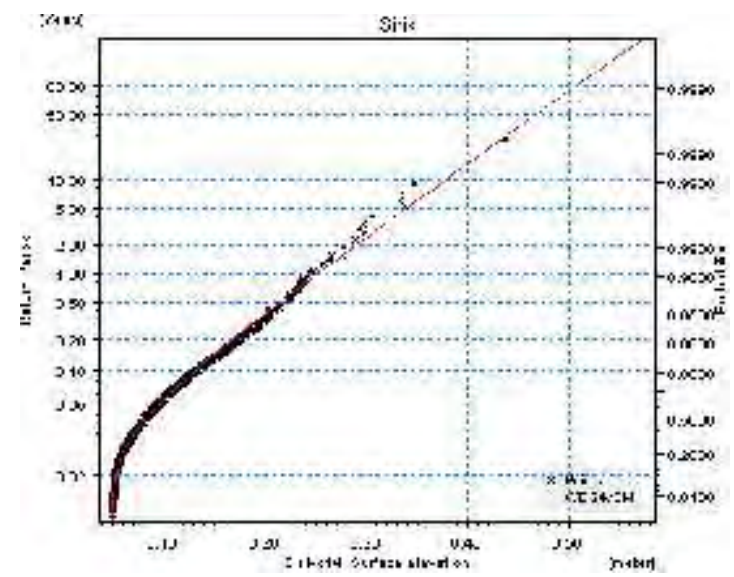

Figure 8) The probability and return period of water level variations for a point in front of Sirik station with depth of $10 \mathrm{~m}$

Table 7) Results of wind setup for a point in front of Sirik station with depth of $10 \mathrm{~m}$

\begin{tabular}{|c|c|}
\hline Return Period (years) & Wind Setup (m) \\
\hline 2 & 0.29 \\
\hline 5 & 0.34 \\
\hline 10 & 0.38 \\
\hline 20 & 0.42 \\
\hline 50 & 0.47 \\
\hline 100 & 0.51 \\
\hline
\end{tabular}

\section{Sea level variations due to barometric pressure}

The nearest synoptic station to this hotpot is Qushm station; so, the measured barometric pressure values in this station during a 15-months period are used to calculate corresponding sea level variations. The probability and return period of sea level variations based on Weibull distribution has been presented in Figure 9. Also, Table 8 represents values of setup due to barometric pressure. It should be mentioned that determining long return interval design data has large uncertainty for such a short record length. 


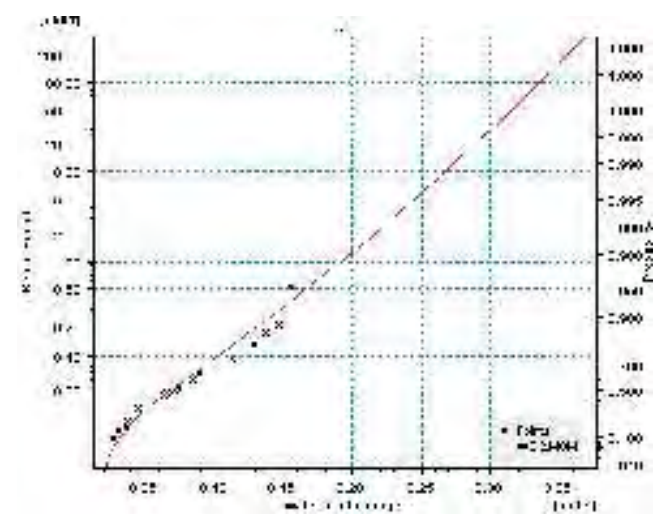

Figure 9) The probability and return period of sea level variations due to barometric pressure in Sirik station

Table 8) Results of setup due to barometric pressure in Sirik station

\begin{tabular}{|c|c|}
\hline Return Period (years) & $\begin{array}{c}\text { Sea level variations } \\
\text { due to barometric } \\
\text { pressure (m) }\end{array}$ \\
\hline 2 & 0.21 \\
\hline 5 & 0.24 \\
\hline 10 & 0.26 \\
\hline 20 & 0.29 \\
\hline 50 & 0.31 \\
\hline 100 & 0.33 \\
\hline
\end{tabular}

\section{The sum of setup}

The sum of setup due to wave, tide and wind with and without setup values due to barometric pressure in Sirik station is presented in Table 9.

Table 9) The sum of setup due to wave, tide and wind with and without sea level variations due to barometric pressure in Sirik station (to CD)*

\begin{tabular}{|c|c|c|c|c|c|c|}
\hline $\begin{array}{c}\text { Return } \\
\text { Period } \\
(\text { years) }\end{array}$ & $\begin{array}{c}\text { Wave } \\
\text { Setup (m) }\end{array}$ & $\begin{array}{c}\text { Tide Setup } \\
(\mathbf{m})\end{array}$ & $\begin{array}{c}\text { Wind } \\
\text { Setup (m) }\end{array}$ & $\begin{array}{c}\text { Setup due to } \\
\text { barometric } \\
\text { pressure (m) }\end{array}$ & $\begin{array}{c}\text { Sum of Setup } \\
\text { with barometric } \\
\text { pressure (m) }\end{array}$ & $\begin{array}{c}\text { Sum of Setup } \\
\text { without } \\
\text { barometric } \\
\text { pressure (m) }\end{array}$ \\
\hline 2 & 0.40 & 3.35 & 0.29 & 0.21 & 4.25 & 3.83 \\
\hline 5 & 0.50 & 3.35 & 0.34 & 0.24 & 4.43 & 3.95 \\
\hline 10 & 0.57 & 3.35 & 0.38 & 0.26 & 4.56 & 4.04 \\
\hline 20 & 0.65 & 3.35 & 0.42 & 0.29 & 4.71 & 4.13 \\
\hline 50 & 0.67 & 3.35 & 0.47 & 0.31 & 4.8 & 4.18 \\
\hline 100 & 0.71 & 3.35 & 0.51 & 0.33 & 4.9 & 4.24 \\
\hline
\end{tabular}

*These values have obtained without water level rise rate

\section{References}

[1] Aung, T. H., Kaluwin, C. and Lennon, G.W., (1998), Climate Change and Sea Level, Part 1: Physical Science, National Tidal Facility, The Flinders University of South Australia, Adelaide, 106 pp. 
[2] Bondar, C., (2007), The Black Sea level variations and the river-Sea interactions, National Institute of Marine Geology and Geo-Ecology (GeoEcoMar), 23-25 Dimitrie Onciul St, 024053 Bucharest, Romania.

[3] Crowder, R.B. 1995. The Wonders of the Weather, Australian Government Publishing Service, Canberra, Chapter 3, 46-48.

[4] GlobOcean., Fara Darya Arsheh., Sogreah., Darya Negar Pars., (2012), The Mean Water Level Variation Report, Monitoring and Modeling Studies of Coastal Zone of HORMOZGAN Province Project.

[5] GlobOcean., Fara Darya Arsheh., Sogreah., Darya Negar Pars., (2010), Tidal Report, Monitoring and Modeling Studies of Coastal Zone of HORMOZGAN Province Project.

[6] GlobOcean., Fara Darya Arsheh., Sogreah., Darya Negar Pars., (2010), Wave Climatology Report, Monitoring and Modeling Studies of Coastal Zone of HORMOZGAN Province Project.

[7] Hareide, D., (2004), Iranian Tide Gauge Network, Norwegian Hydrographic Service.

[8] Huang, W., Xu, S., Nnaji, S., (2008), Evaluation of GEV model for frequency analysis of annual maximum water levels in the coast of United States, Ocean Engineering, Volume 35, Issues 11$12,1132-1147$.

[9] Ilia, A., Mazaheri, S., \& Allahyar, M. R. (2010). Comparison of statistical (QQ plot) and classical calibration methods in wave modeling. In 9th International Conference on Coasts, Ports and Marine Structures (ICOPMAS).

[10] Sorensen, Robert M., (2006), Basic Coastal Engineering, 3rd ed, XIV, 324 p.

[11] Zervas, C., (2001), Sea Level Variations of the United States 1854-1999, NOAA Technical Report NOS CO-OPS. 